Supporting information

\title{
Discovery of dipeptides as potent botulinum neurotoxin A light chain inhibitors
}

Martin Amezcua, Ricardo S. Cruz, Alex Ku, Wilfred Moran, Marcos E. Ortega, Nicholas T. Salzameda*

Department of Chemistry \& Biochemistry, California State University, Fullerton, CA 92831, United States

*Corresponding author: nsalzameda@fullerton.edu

\section{Table of contents}

1. Synthesis of Dipeptides

SI2-3

2. ${ }^{1} \mathrm{H} /{ }^{13} \mathrm{C}$ NMR spectroscopy and HRMS for 30-33.

3. Enzymatic assay procedures for BoNT/A LC inhibitors........SI5

4. Expression/purification of BoNT/A LC and crystallization/structure solutions....SI5-6

5. Representative analytical HPLC spectra of dipeptides....SI7-13

6. NMR spectra of dipeptides 30-33.......SI14-16 


\section{Synthesis of Dipeptides}

Materials

The hydroxylamine Wang Resin acids purchased from Novabiochem. The peptide coupling reagents 6-Chloro-1-Hydroxybenzotriazole was purchased from Ochem Inc and N,N'Diisopropylcarbodiimide was purchased from Advanced Chem Tech and used without further purification. The sulfonyl chlorides were purchased from Aldrich and all other solvents and reagents were purchased from Fisher Scientific and used without further purification. An Inititator microwave reactor from Biotage was used in the synthesis of the library. The small molecules were purified by a Shimadzu prep HPLC with a C18 reverse phase column (VYDAC cat \# 218TP101522) using water and acetonitrile as the mobile phase. The BoNT/A LC and SNAPtide substrate using the enzymatic assays were purchased from List Biological Laboratories, Inc.

All Fmoc-amino acids and hydroxylamine Wang Resin were obtained from Chem-Impex. 6-Chloro-1-Hydroxybenzotriazole (HOBt) was purchased from Ochem Inc and N,N'Diisopropylcarbodiimide (DIC) was purchased from Advanced Chem Tech. All other reagents were purchased from Fisher and used without further purification. All hydroxamic acids were purified by a Shimadzu preparatory HPLC with a C18 reverse phase column (VYDAC cat \# 218TP101522) HPLC, Total Flow, 10mL/min; monitored at 254 and $214 \mathrm{~nm}$ wavelengths. A two solvent system was used with water (A) and acetonitrile (B). The gradient was as follows: B concentration progresses to $10 \%$ from $0.00-5.00$ minutes, $\mathrm{B}$ concentration progresses to $80 \%$ from 5.00-38.00 minutes, B concentration progresses to $90 \%$ from $38.00-42.00$ minutes, $\mathrm{B}$ concentration progresses to $90 \%$ from $42.00-50.00$ minutes, B concentration progresses to $10 \%$ from 50.00-55.00 minutes, B concentration stays at 10\% from 55.00-58.00 minutes. Fractions were collected and lyophilized to obtain solid material. NMR spectra was recorded utilizing a Bruker $400 \mathrm{MHz}$ NMR operating at $400 \mathrm{MHz}$ for proton NMR and $100 \mathrm{MHz}$ for carbon NMR in either $\mathrm{CDCl}_{3}$ or $\mathrm{d}_{6}$-DMSO solvent as indicated. High resolution mass spectra (HRMS) data was collected by a Q Exactive Focus mass spectrometer.

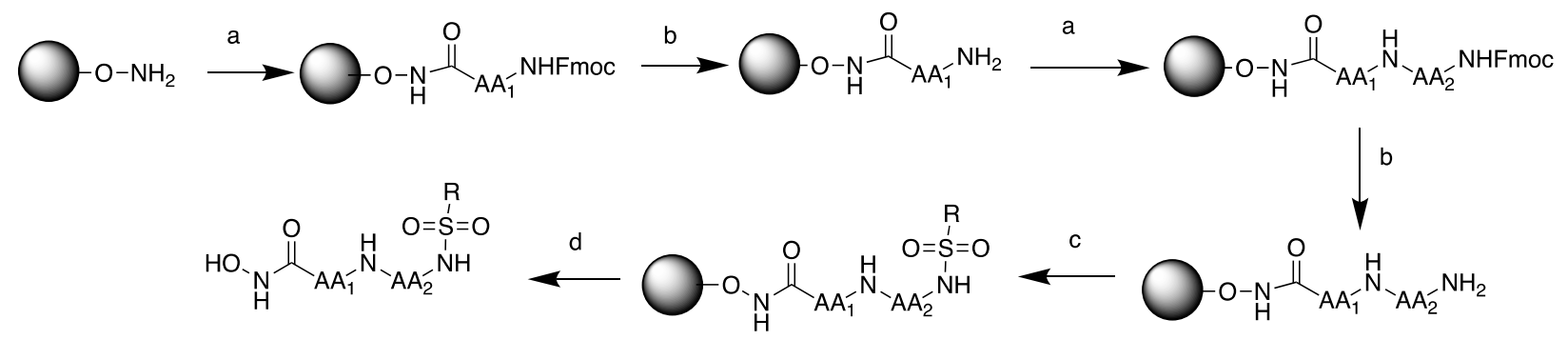

Reagents and conditions: (a) Fmoc-protected amino acid, HOBt, DIC, DMF; (b) 25\% PIP in DMF; (c) sulfonyl chloride, 2,6-lutidine, DCM; (d) 50\% TFA in DCM.

Loading Fmoc-amino acid to resin. 
$100 \mathrm{mg}(0.19 \mathrm{mmol})$ of the Hydroxylamine Wang resin of (resin load: $1.9 \mathrm{mmol} / \mathrm{g}$ ) was placed into a $12 \mathrm{ml}$ reaction syringe. $3 \mathrm{~mL}$ of dichloromethane (DCM) was added to the syringe and shaken for 10 minutes to swell the resin and the than the solution was expelled from the syringe. 6-Chloro-1-Hydroxybenzotriazole (3 equivalents), FMOC-protected amino acid (3 equivalents), and diisopropycarbodiimide (3 equivalents) were dissolved in $3 \mathrm{~mL}$ of dimethylformamide (DMF) and stirred for 10 minutes at room temperature. The solution was add to the syringe with the swelled resin and shaken for 1.5 hours. The solution was expelled from the syringe and the resin washed with DMF, DCM, and DMF.

\section{$\underline{\text { Removing Fmoc group }}$}

The Fmoc group attached to the coupled amino acid was removed by adding a $25 \%$ piperidine solution in DMF $(8 \mathrm{ml})$ to the syringe with the resin and shaking for 10 minutes. This was step was performed twice to ensure complete removal of Fmoc group. The resin was washed with DMF x 3, DCM x 3 and DMF x 3 .

Coupling Sulfonyl Chloride to amino acid attached to the resin

Following removal of Fmoc group from the final amino acid on resin, sulfonyl chloride (equivalents) and 2,6-Lutidine (amount) were dissolved in $3 \mathrm{~mL}$ of DCM and stirred for 10 minutes at room temperature. The sulfonyl chloride solution was added to the syringe and shaken for 24 hours. The solution was removed and the resin washed with DMF x 3 and DCM x 3 .

Cleavage of resin from Hydroxylamine Wang Resin

The completed dipeptide was cleaved from the resin by adding a 50\% Trifluoroacetic Acid in DCM solution ( $3 \mathrm{ml}$ ) to the syringe and was shaken for 1.5 hours. The solution in the syringe was transferred to a round bottom flask and the solvent was removed by rotary evaporator. Cold anhydrous diethyl ether was added to the round bottom flask to precipitate the product. The ether and the precipitate was transferred to a falcon tube and centrifuged so that the ether can be decanted leaving the precipitate in the falcon tube. Additional cold ether was added to the falcon tube to wash the crude product and centrifuge decantation steps were repeated two more times.

\section{Characterization and Purification}

Dipeptides were purified by Prep-HPLC using a C18 reverse phase VYDAC HPLC column at a flow rate of $10 \mathrm{ml} / \mathrm{min}$. The crude product was dissolved in $1 \mathrm{ml}$ of DMSO and injected into the prep HPLC. A two solvent system was used with $0.1 \%$ TFA/water (A) and acetonitrile (B). The gradient was as follows: B concentration progresses to $10 \%$ from $0.00-5.00$ minutes, $\mathrm{B}$ concentration progresses to $80 \%$ from 5.00-38.00 minutes, B concentration progresses to $90 \%$ from 38.00-42.00 minutes, B concentration progresses to $90 \%$ from 42.00-50.00 minutes, B concentration progresses to $10 \%$ from 50.00-55.00 minutes, B concentration stays at $10 \%$ from 55.00-58.00 minutes. Fractions were collected and lyophilized to obtain 15-53 mg of dipeptide (20-70\% yield)

Dipeptides were analyzed for purity by analytical HPLC with a RP C18 column measuring 214 $\mathrm{nm} 254 \mathrm{~nm}$ wavelengths. The HPLC parameters were set with an injection volume of $10 \mu \mathrm{L}$, flow rate of $0.500 \mathrm{~mL} / \mathrm{min}$ using a gradient method with $0.1 \% \mathrm{TFA} / \mathrm{H}_{2} \mathrm{O}$ (solvent A) and Acetonitrile (solvent B). The gradient was 10\%-90\% solvent B over 30 minutes. 


\section{2. ${ }^{1} \mathrm{H} /{ }^{13} \mathrm{C}$ NMR spectroscopy and HRMS for dipeptides 30-33}

30: (2S,3S)-2-((3,5-dichlorophenyl)sulfonamido)-N-((S)-1-(hydroxyamino)-1-oxopentan-2-yl)3-methylpentanamide

${ }^{1} \mathrm{H}$ NMR (400 MHz, DMSO-d6) $\delta 10.56(\mathrm{~s}, 1 \mathrm{H}), 8.81(\mathrm{~s}, 1 \mathrm{H}), 8.23-8.11(\mathrm{~m}, 2 \mathrm{H}), 7.89(\mathrm{t}, J=$ $1.9 \mathrm{~Hz}, 1 \mathrm{H}), 7.73(\mathrm{dd}, J=1.9,0.8 \mathrm{~Hz}, 2 \mathrm{H}), 3.84(\mathrm{~d}, J=7.6 \mathrm{~Hz}, 1 \mathrm{H}), 3.41(\mathrm{~d}, J=19.8 \mathrm{~Hz}, 1 \mathrm{H})$, $3.30(\mathrm{~d}, J=10.6 \mathrm{~Hz}, 3 \mathrm{H}), 1.59-0.88(\mathrm{~m}, 2 \mathrm{H}), 0.78(\mathrm{dd}, J=9.6,6.7 \mathrm{~Hz}, 11 \mathrm{H})$.

${ }^{13} \mathrm{C}$ NMR (101 MHz, DMSO) $\delta 169.28,167.77,144.45,134.53,131.67,125.23,59.79,49.60$, $37.27,34.37,24.10,18.42,15.03,13.61,10.50$.

HRMS $\mathrm{C}_{17} \mathrm{H}_{25} \mathrm{Cl}_{2} \mathrm{~N}_{3} \mathrm{O}_{5} \mathrm{~S}[\mathrm{M}+\mathrm{H}]^{+}$:Calculated 454.0965, observed 454.0960.

31:_(2S,3S)-2-((S)-2-((3,5-dichlorophenyl)sulfonamido)-3-methylbutanamido)-N-hydroxy-3methylpentanamide

${ }^{1} \mathrm{H}$ NMR (400 MHz, DMSO-d6) $\delta 10.64$ (s, 1H), 8.89 (s, 1H), 8.24 (d, $\left.J=9.3 \mathrm{~Hz}, 1 \mathrm{H}\right), 8.13$ (d, $J$ $=8.9 \mathrm{~Hz}, 1 \mathrm{H}), 7.94(\mathrm{t}, J=1.9 \mathrm{~Hz}, 1 \mathrm{H}), 7.82(\mathrm{~d}, J=1.9 \mathrm{~Hz}, 2 \mathrm{H}), 3.92-3.81(\mathrm{~m}, 2 \mathrm{H}), 1.94-1.78$ $(\mathrm{m}, J=6.6 \mathrm{~Hz}, 1 \mathrm{H}), 1.56-1.41(\mathrm{~m}, 1 \mathrm{H}), 1.17(\mathrm{dtd}, J=12.9,9.5,8.5,3.6 \mathrm{~Hz}, 1 \mathrm{H}), 0.93-0.69$ $(\mathrm{m}, 13 \mathrm{H})$.

${ }^{13} \mathrm{C}$ NMR (101 MHz, DMSO) $\delta$ 169.37, 167.16, 144.47, 134.58, 131.68, 125.22, 60.75, 54.13, $36.57,31.50,24.30,19.06,17.96,14.90,10.87$.

HRMS C ${ }_{17} \mathrm{H}_{25} \mathrm{Cl}_{2} \mathrm{~N}_{3} \mathrm{O}_{5} \mathrm{~S}[\mathrm{M}+\mathrm{H}]^{+}$:Calculated 454.0965, observed 454.0964.

32: (S)-2-((S)-2-((3,5-dichlorophenyl)sulfonamido)-3-phenylpropanamido)-N-

hydroxypentanamide

${ }^{1} \mathrm{H}$ NMR (400 MHz, DMSO-d6) $\delta 10.64(\mathrm{~s}, 1 \mathrm{H}), 8.88$ (s, 1H), 8.51 (d, $\left.J=9.3 \mathrm{~Hz}, 1 \mathrm{H}\right), 8.33$ (d, $J$ $=8.3 \mathrm{~Hz}, 1 \mathrm{H}), 7.77(\mathrm{t}, J=1.9 \mathrm{~Hz}, 1 \mathrm{H}), 7.48(\mathrm{~d}, J=1.9 \mathrm{~Hz}, 2 \mathrm{H}), 7.22-7.06(\mathrm{~m}, 5 \mathrm{H}), 4.20$ (ddd, $J=10.8,9.2,3.7 \mathrm{~Hz}, 1 \mathrm{H}), 4.00(\mathrm{td}, J=8.0,6.6 \mathrm{~Hz}, 1 \mathrm{H}), 2.84(\mathrm{dd}, J=13.9,3.7 \mathrm{~Hz}, 1 \mathrm{H}), 2.60$ $(\mathrm{dd}, J=13.9,10.9 \mathrm{~Hz}, 1 \mathrm{H}), 1.54-1.28(\mathrm{~m}, 2 \mathrm{H}), 1.27-1.05(\mathrm{~m}, 2 \mathrm{H}), 0.85(\mathrm{t}, J=7.3 \mathrm{~Hz}, 3 \mathrm{H})$. ${ }^{13} \mathrm{C}$ NMR (101 MHz, DMSO) $\delta 169.99,167.89,144.19,136.96,134.48,131.59,129.14,127.73$, $126.40,124.83,57.24,49.88,38.40,34.59,18.49,13.65$.

HRMS C ${ }_{20} \mathrm{H}_{23} \mathrm{Cl}_{2} \mathrm{~N}_{3} \mathrm{O}_{5} \mathrm{~S}[\mathrm{M}+\mathrm{H}]^{+}$:Calculated 488.0808, observed 488.0808.

33: (S)-2-((S)-2-((3,5-dichlorophenyl)sulfonamido)-3-phenylpropanamido)-N-hydroxy-3methylbutanamide

${ }^{1} \mathrm{H}$ NMR (400 MHz, DMSO-d6) $\delta 10.65$ (s, 1H), 8.90 (s, 1H), 8.51 (d, $\left.J=9.1 \mathrm{~Hz}, 1 \mathrm{H}\right), 8.29$ (d, $J$ $=9.0 \mathrm{~Hz}, 1 \mathrm{H}), 7.74(\mathrm{t}, J=1.9 \mathrm{~Hz}, 1 \mathrm{H}), 7.44(\mathrm{~d}, J=1.9 \mathrm{~Hz}, 2 \mathrm{H}), 7.20-7.04(\mathrm{~m}, 4 \mathrm{H}), 4.25$ (ddd, $J=10.8,9.0,3.6 \mathrm{~Hz}, 1 \mathrm{H}), 3.94-3.85(\mathrm{~m}, 1 \mathrm{H}), 2.81(\mathrm{dd}, J=13.8,3.6 \mathrm{~Hz}, 1 \mathrm{H}), 2.65-2.55(\mathrm{~m}$, $1 \mathrm{H}), 2.51(\mathrm{p}, J=1.8 \mathrm{~Hz}, 1 \mathrm{H}), 1.90-1.73(\mathrm{~m}, J=6.5 \mathrm{~Hz}, 1 \mathrm{H}), 0.80(\mathrm{dd}, J=6.7,3.7 \mathrm{~Hz}, 6 \mathrm{H})$.

${ }^{13} \mathrm{C}$ NMR (101 MHz, DMSO) $\delta 170.24,167.22,144.20,136.88,134.49,131.53,129.11,127.64$, $126.39,124.74,57.26,55.52,38.34,30.83,18.97,18.46$.

HRMS C ${ }_{20} \mathrm{H}_{23} \mathrm{Cl}_{2} \mathrm{~N}_{3} \mathrm{O}_{5} \mathrm{~S}[\mathrm{M}+\mathrm{H}]^{+}$:Calculated 488.0808, observed 488.0806. 


\section{Enzymatic assay}

Dipeptides (10 mM DMSO stock solutions) were evaluated for inhibitor activity with a commercially available FRET-based enzymatic assay (List Laboratories, California) in a 96 well plate format. Assays were performed in $50 \mathrm{mM}$ HEPES buffer at $\mathrm{pH} 7.4$ with $0.5 \%$ TWEEN 20, with BoNT/LC A (20 nM) (List laboratories, product \#610A.), SNAPTide $(8 \mu \mathrm{M})$ ( (List laboratories, product \#523) and dipeptide $(15 \mu \mathrm{M})$ in a total volume of $100 \mu \mathrm{L}$. The reactions were initiated by the addition of SNAPtide to the well containing the BoNT/A LC, inhibitor and buffer for a total volume of $100 \mu \mathrm{L}$ with $3 \%$ or less of DMSO. The reactions were monitored by a Spectramax M2 plate reader (Molecular Devices, Sunnyvale, CA, USA) using an excitation of $490 \mathrm{~nm}$ and emission of $523 \mathrm{~nm}$ for $10 \mathrm{~min}$ to obtain fluorescence as a function of time. The initial rates (0-5 mins) for each enzyme reaction were compared to a control (no inhibitor present) and run in triplet to determine the percent inhibition.

The $\mathrm{IC}_{50}$ values were determined by performance the enzyme described previous at various inhibitor concentrations in triplicate. The rate at each inhibitor concentration was performed in triplicate and normalized to the rate of the control. The log (inhibitor) vs. normalized response variable rate model was fit to the normalized rate data in triplicate to calculate the $\mathrm{IC}_{50}$ using Prism 6.0 (Graftpad, San Diego, CA).

\section{Expression/purification of BoNT/A LC and crystallization/structure solutions}

\section{Expression and Purification of BoNT/A LC:}

The plasmid that expresses the first 424 amino acids with a $C$ terminal six his tag was purchased from Addgene. The plasmid was transformed into BL21(DE3) cells and the protein was cultured in Luria broth supplemented with $300 \mathrm{mM} \mathrm{NaCl}$. Cells were grown to an optical density of 0.4 and then induced with $0.25 \mathrm{mM}$ IPTG. Cells were induced at $14^{\circ} \mathrm{C}$ for 16 hours with shaking. Cells were harvested and resuspended in 20mM Tris $\mathrm{pH} 8.0,500 \mathrm{mM} \mathrm{NaCl}$, and $10 \%$ glycerol, then lysed using a Dihydromatics Fluidizer. BoNT LC was purified via affinity chromatography using HisPur Ni-NTA resin from Thermo Fisher Scientific. Pure fractions of BoNT LC were identified via SDS-PAGE analysis with $15 \%$ gels. Pure fractions were dialyzed into $20 \mathrm{mM}$ Tris pH8, $500 \mathrm{mM} \mathrm{NaCl}, 1 \mathrm{mM}$ EDTA, and 5\% glycerol. Protein was concentrated to $1 \mathrm{~mL}$ via centrifugal concentrations from Vivaspin and then applied to an equilibrated HiLoad Superdex 200 prep column purchased from GE Healthcare. Pure BoNT was identified via 15\% SDS-PAGE analysis and fractions were pooled and concentrated to $100 \mathrm{uM}$ using a centrifugal concentrator from Vivaspin. Protein was aliquoted and stored at $-20^{\circ} \mathrm{C}$.

\section{Crystallization and Structure Solution of of BoNT LC:}

The purified BoNT was diluted to $10 \mathrm{mg} / \mathrm{mL}$ and then screened using sitting drop 96 well trays and high through-put blocks from Molecular Dimensions. Crystals were optimized with 24 well trays from Hampton Research using the hanging drop method. The crystals optimally formed in $50 \mathrm{mM}$ sodium cacodylate $\mathrm{pH}$ 7.0, $200 \mathrm{mM}$ ammonium sulfate, and 30\% PEG 8000. Crystals were harvested and then soaked overnight with $1 \mathrm{mM}$ of the dipeptide inhibitors. Crystals were cryo harvested the next day and stored in liquid nitrogen. Data was collected at Lawrence Berkeley National Laboratory (ALS) on beamline 4.2.2. Diffraction data was processed with 
HKL 2000 and molecular replacement was used to determine phasing using PDB 4HEV using CCP4 and Phaser. Coot was used to model in inhibitors and Refmac was used to refine structure.

Table S1. Data Collection and Refinement Statistics.

\begin{tabular}{|l|c|c|c|c}
\hline Protein & BoNT Apo (PDB \#7KY2) & BoNT-33 (PDB \#7KYH) & BoNT-30 (PDB \#7KYF) \\
\hline Wavelength & 0.97 & 0.97 & 0.97 \\
\hline Resolution range & $49-2.78$ & $48.1-2.91$ & $43.2-2.33$ \\
\hline Space group & P1211 & P1 & P21212 \\
\hline Unit cell & 21425 & 35480 & 57.53196 .4038 .78909090 \\
\hline Unique reflections & 99.3 & 95.2 & 19587 \\
\hline Completeness (\%) & 20732 & 33183 & 99.7 \\
\hline Reflections used in refinement & 1512 & 2297 & 17628 \\
\hline Reflections used for R-free & 0.1276 & 0.1385 & 1958 \\
\hline R-work & 0.167 & 0.1598 & 0.1646 \\
\hline R-free & 0.013 & 0.011 & 0.1895 \\
\hline RMS(bonds) & 1.7 & 1.9 & \\
\hline RMS(angles) & 47.9 & 61.6 & \\
\hline Average B-factor & & & \\
\hline
\end{tabular}
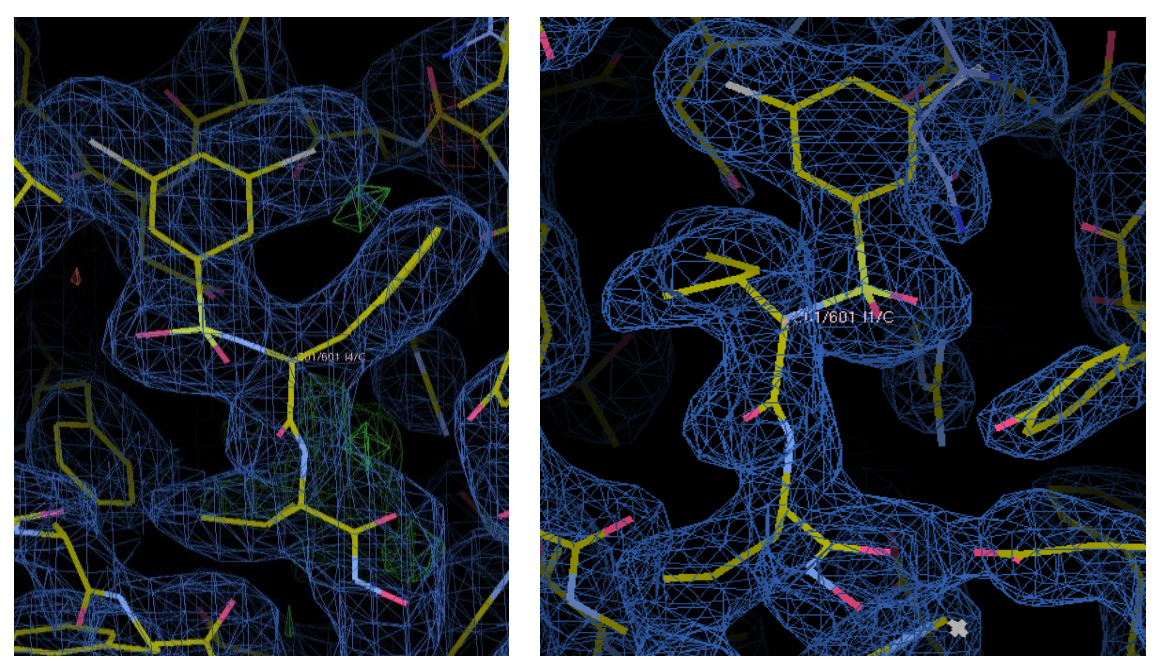

Figure S1. Electron Density of Dipeptide Inhibitors. Left. 33

inhibitor with sigma of 1.3. Right. 30 with sigma of 1.3 


\section{Representative analytical HPLC spectra of dipeptides}

2
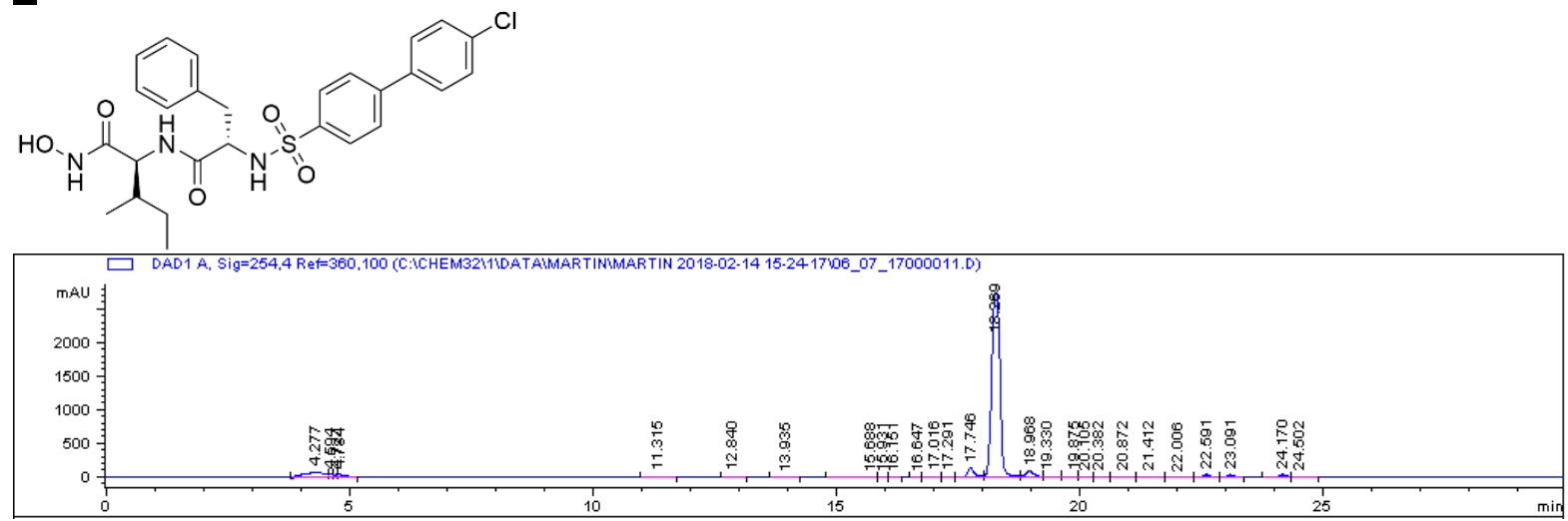

3

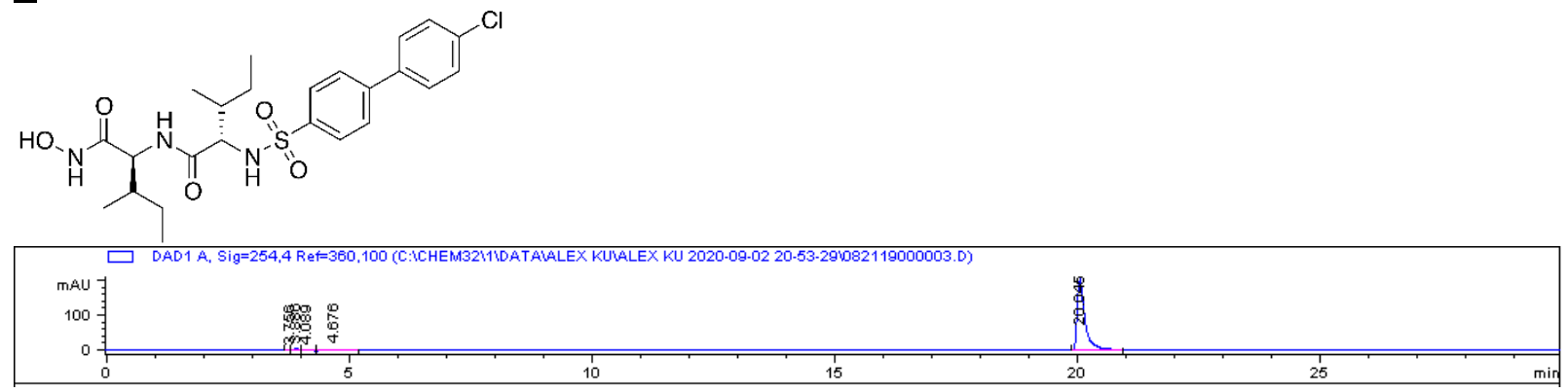

$\underline{4}$

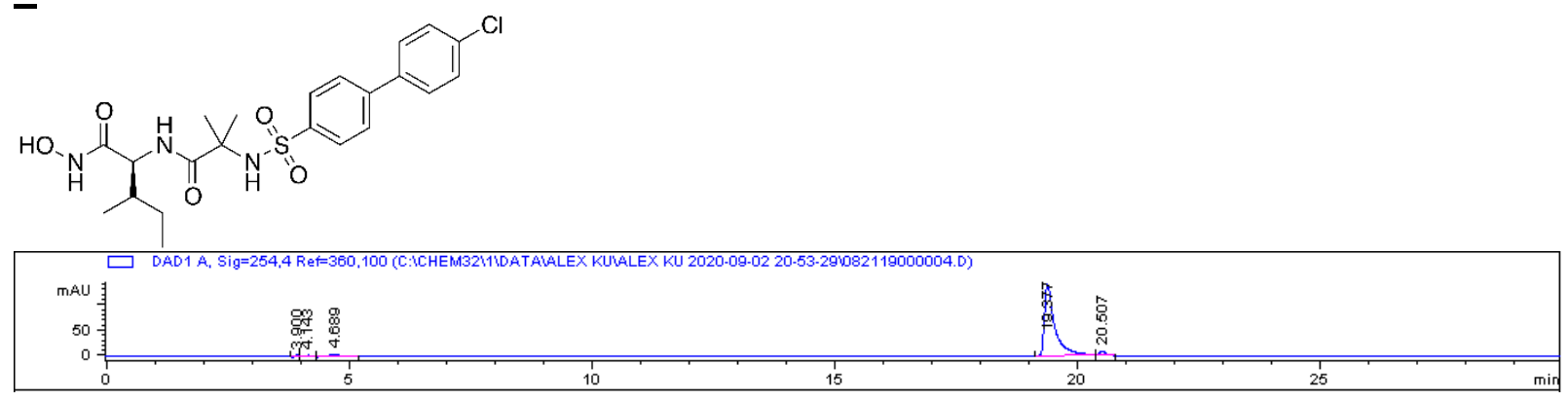

$\underline{5}$<smiles>CCC(C)[C@H](NS(=O)(=O)c1ccc(-c2ccc(Cl)cc2)cc1)C(=O)N[C@@H](C)C(=O)NO</smiles> 


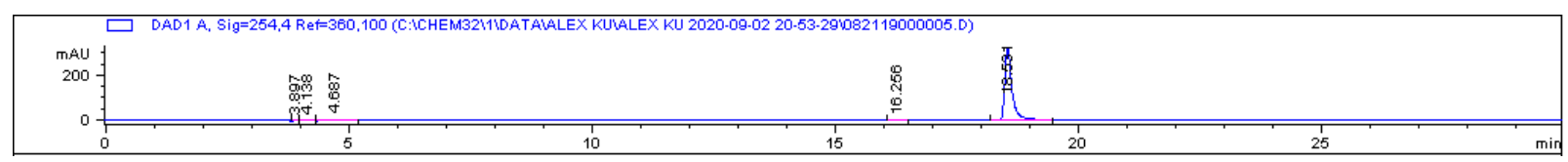

\section{6}

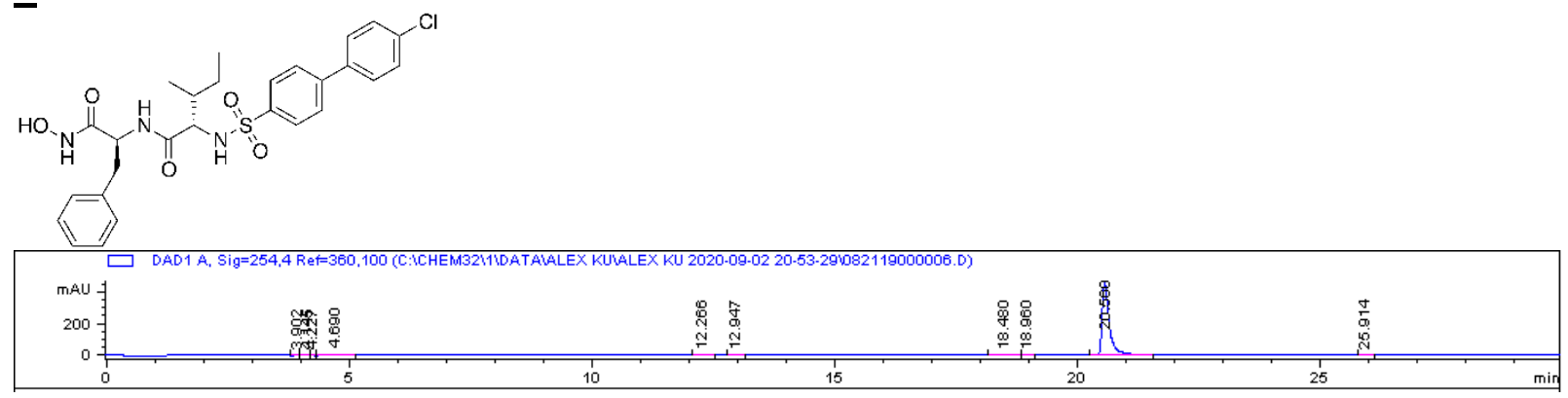

7:

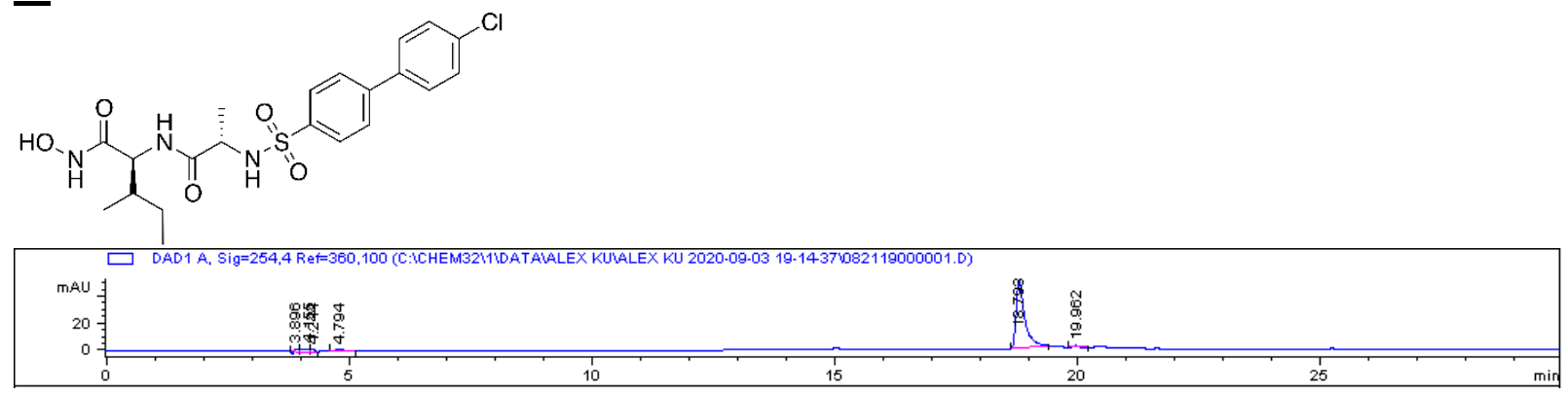

9:

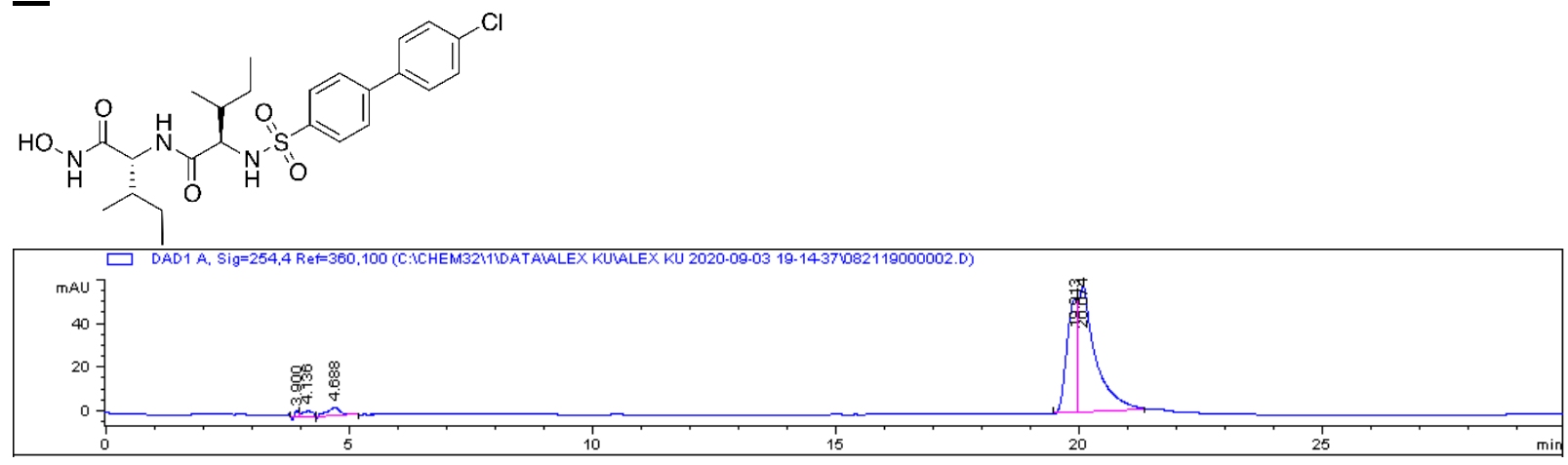

10:

(O) 


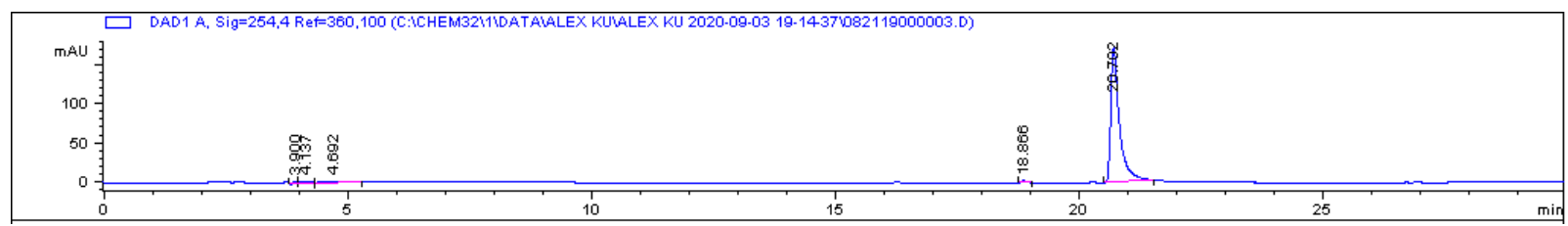

11

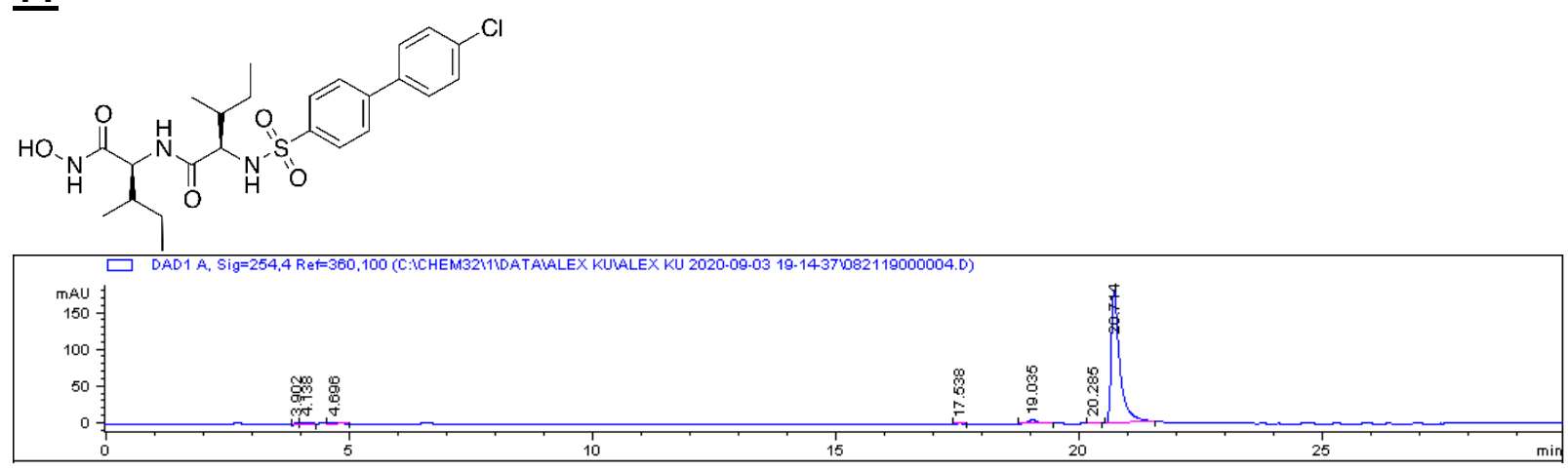

13:

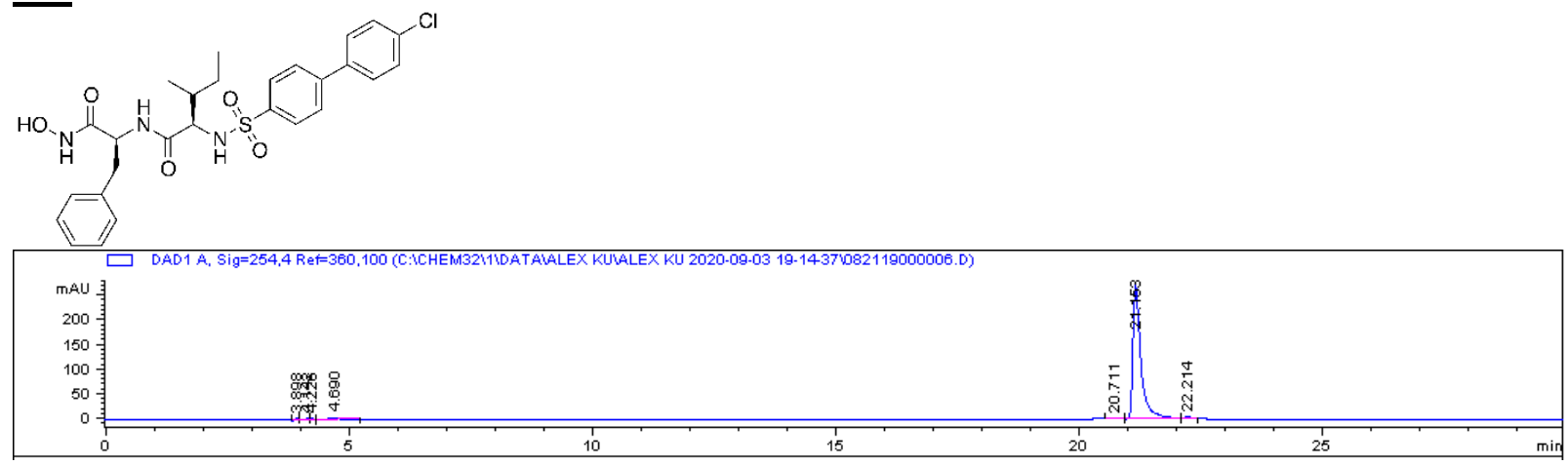

17

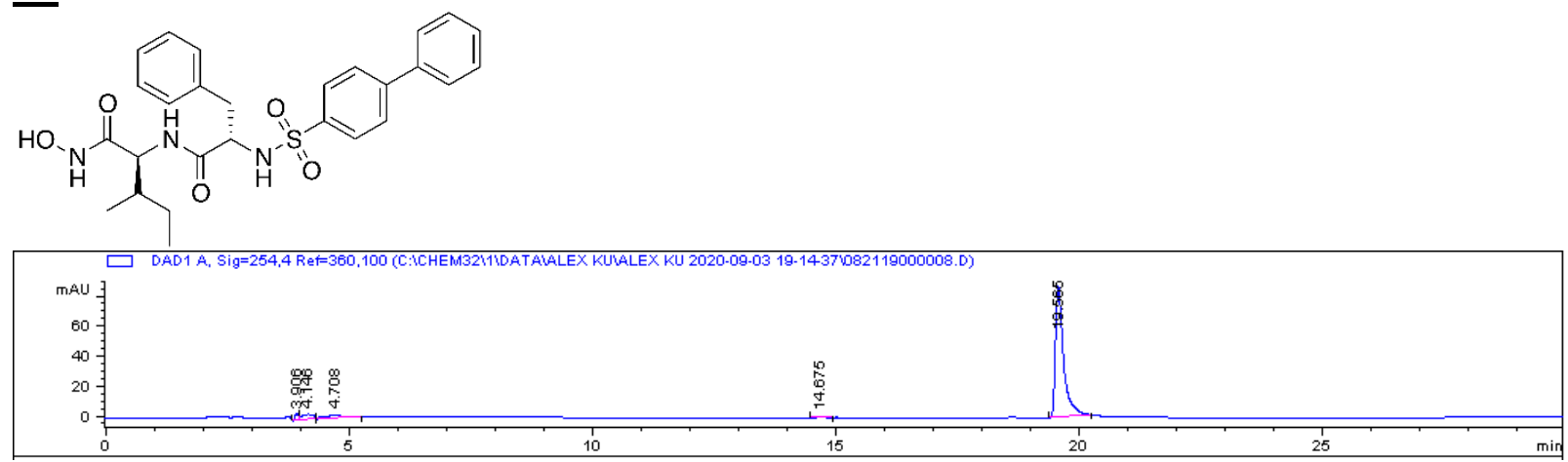

18

(1) 


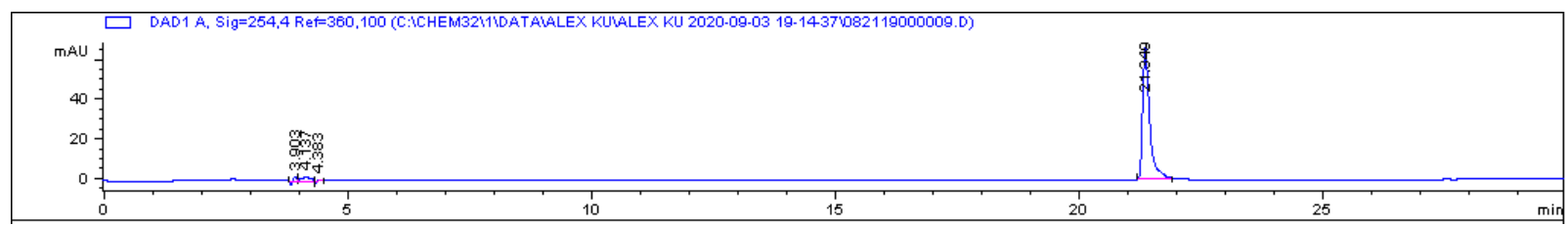

20<smiles>CCC(C)C(NC(=O)C(Cc1ccccc1)NS(=O)(=O)c1cc(Cl)cc(Cl)c1)C(=O)NO</smiles>

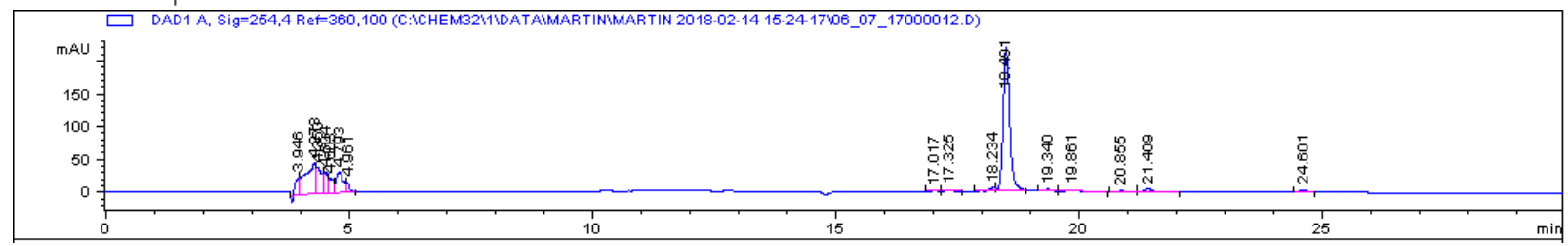

\section{1}
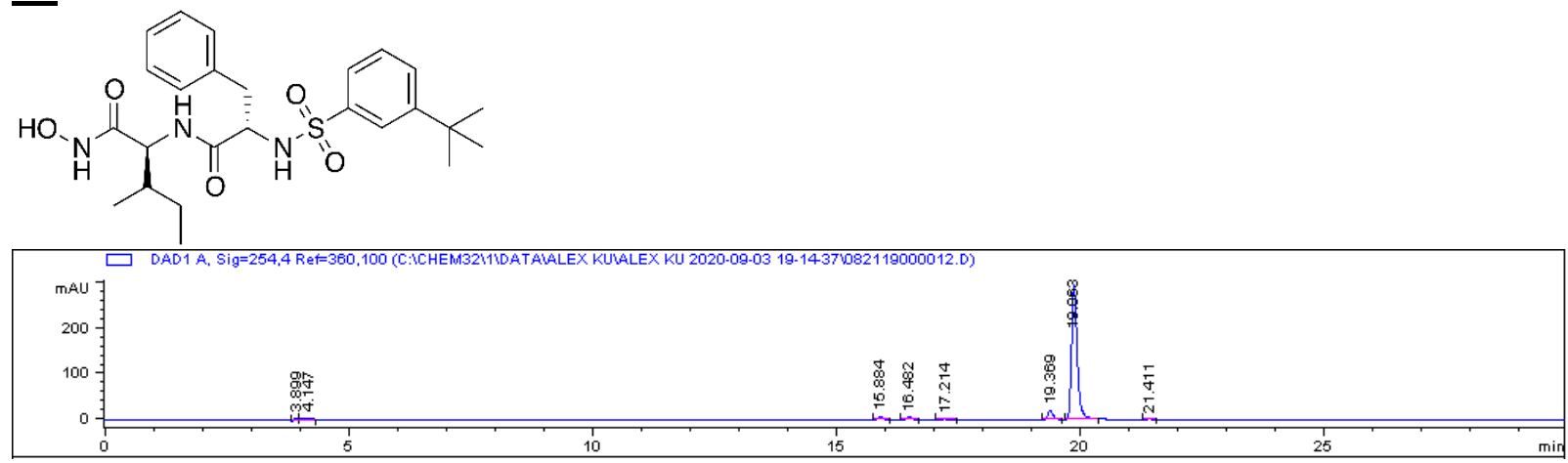

\section{$\underline{23}$}

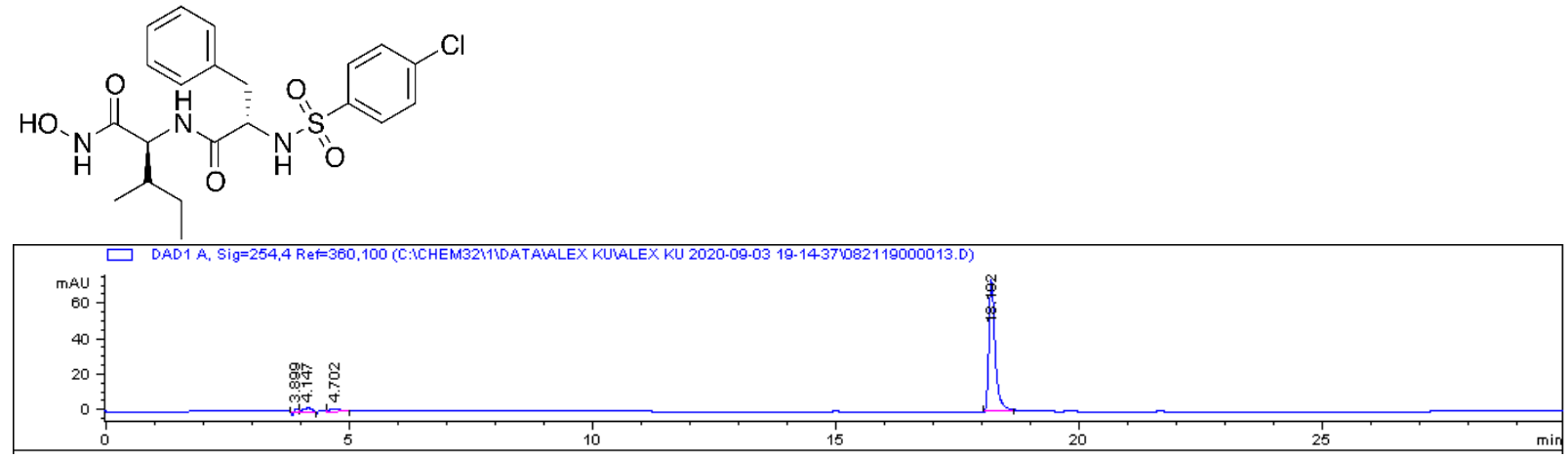

$\underline{24}$ 

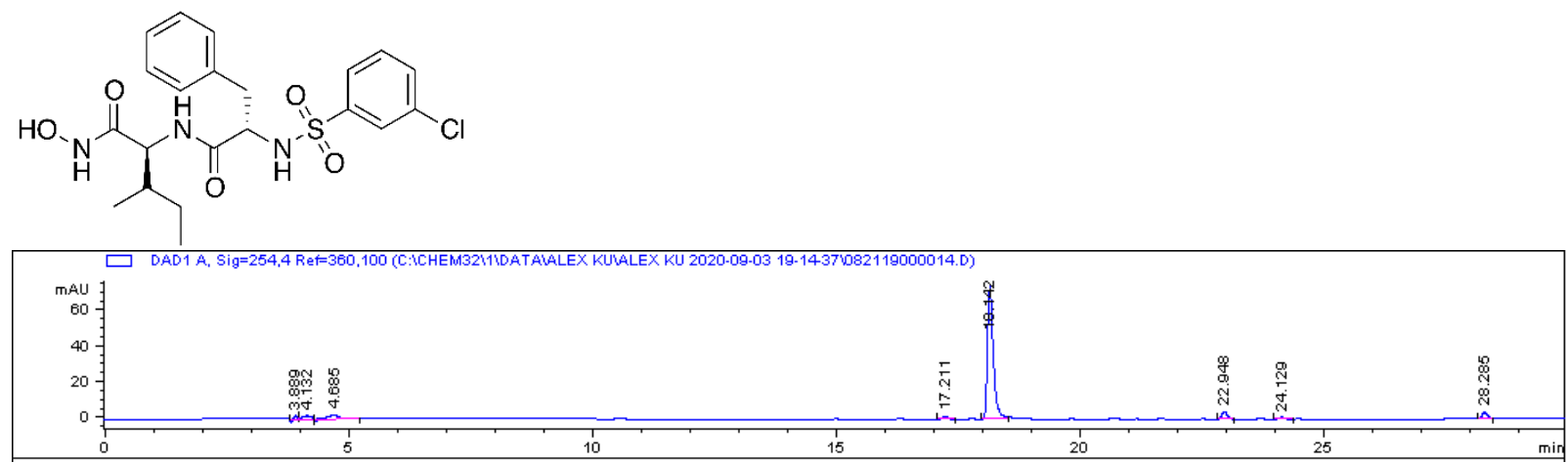

\section{5}

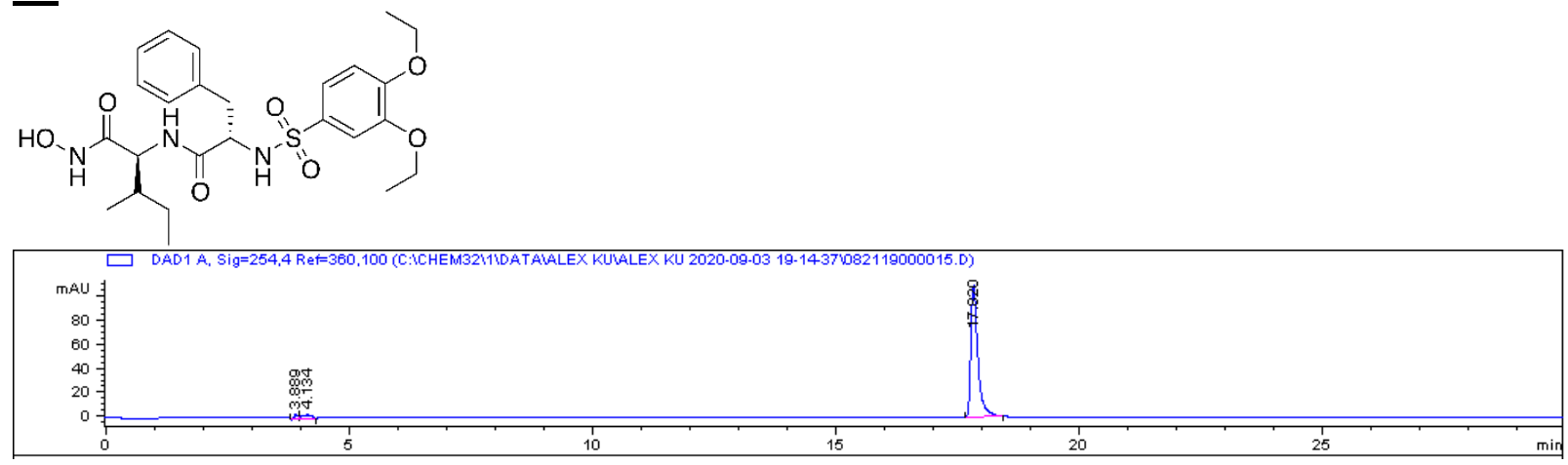

27
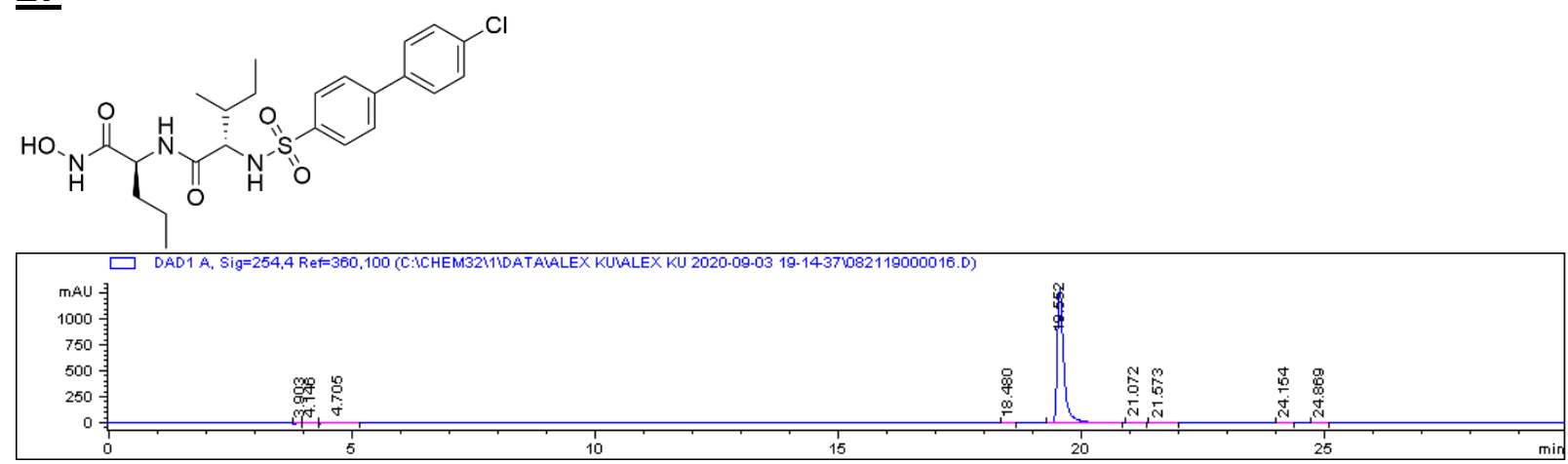

$\underline{28}$
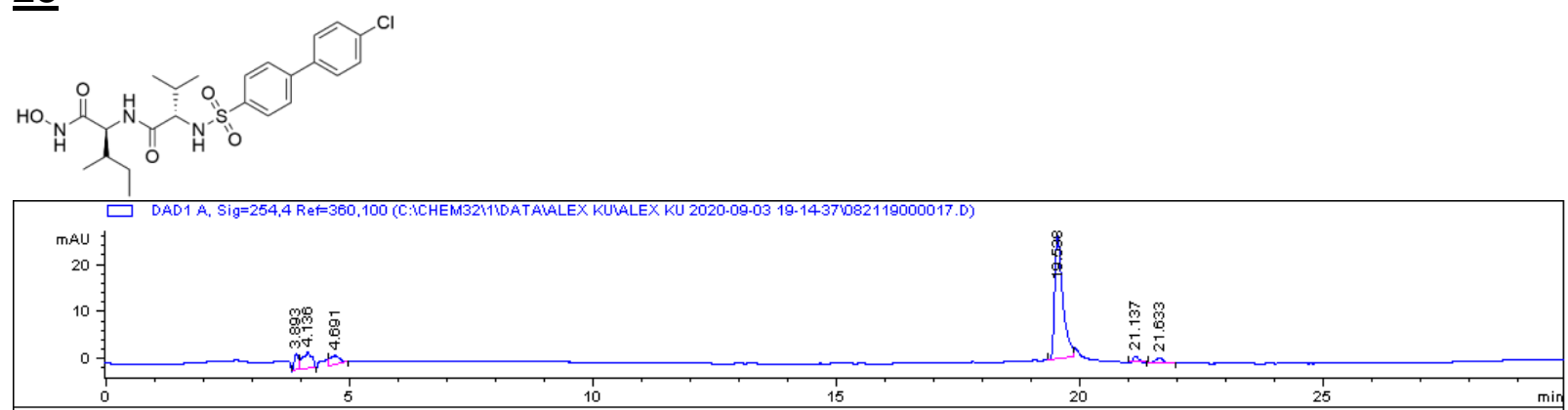

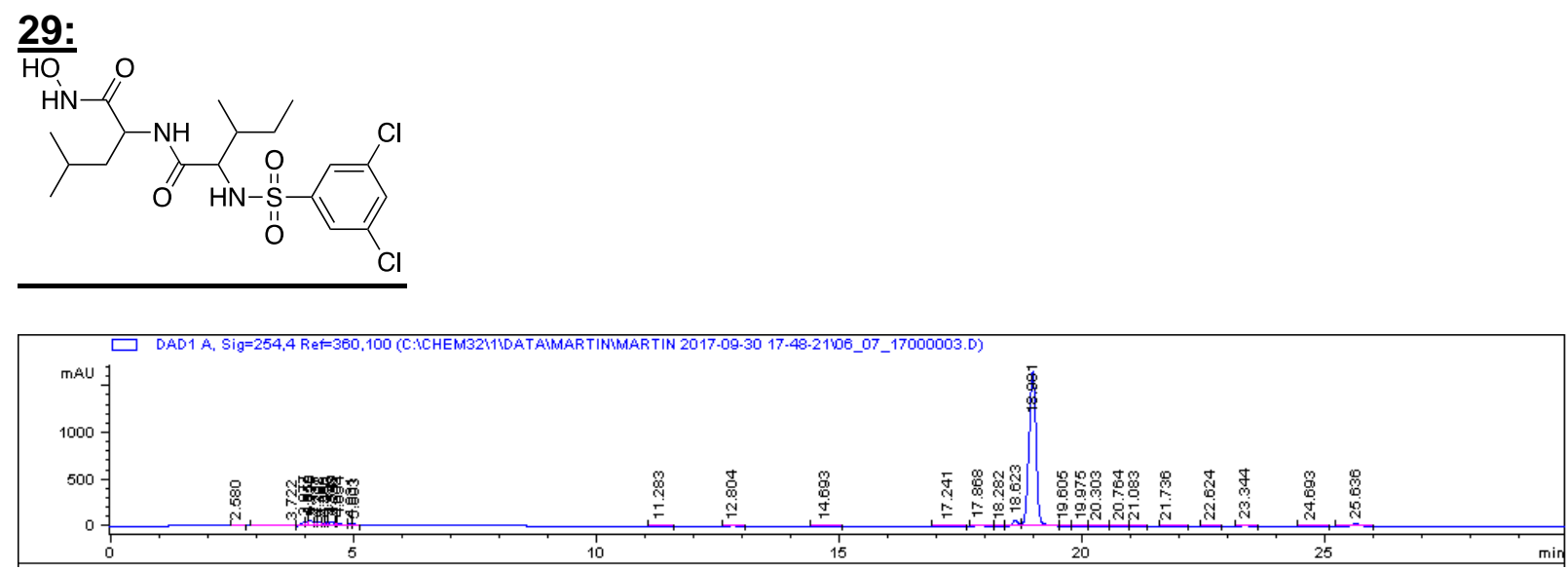

30*:
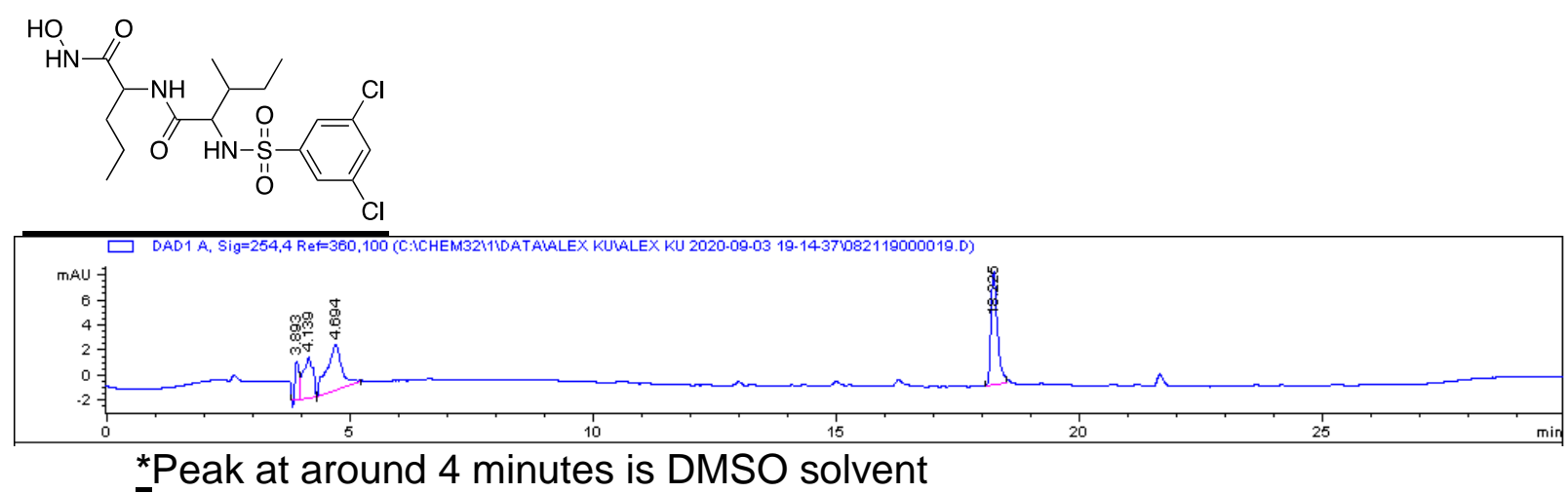

\section{1:}
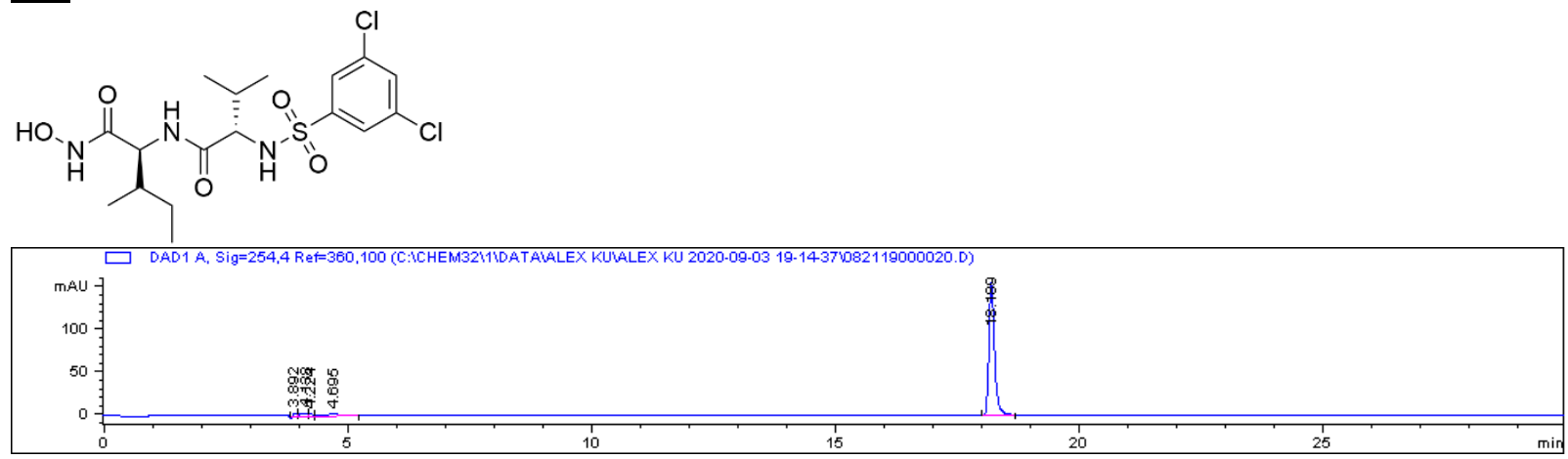
32*:
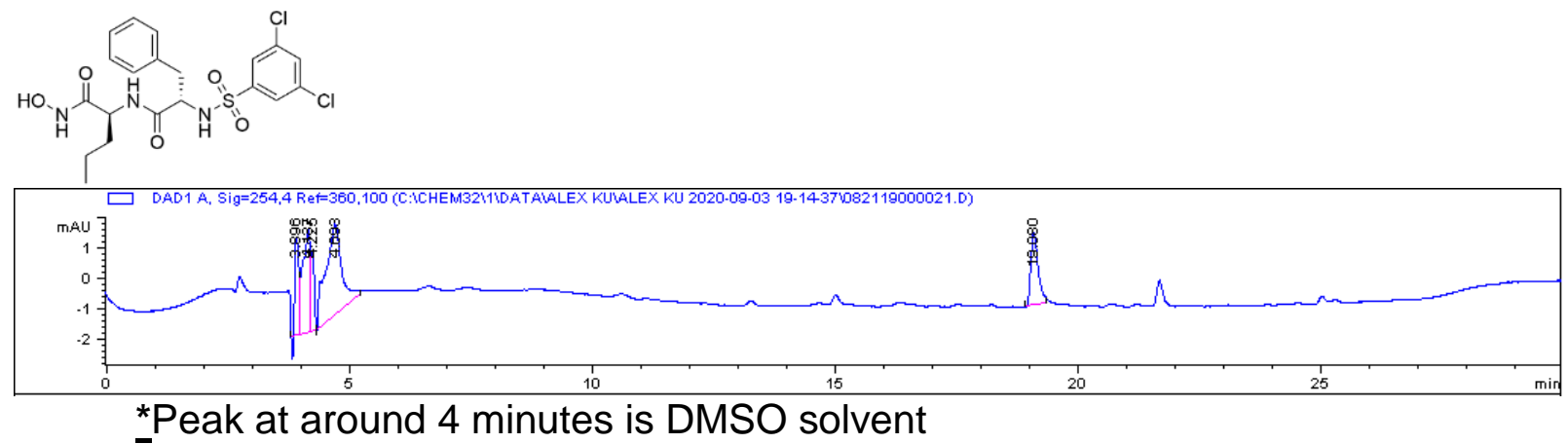

33:

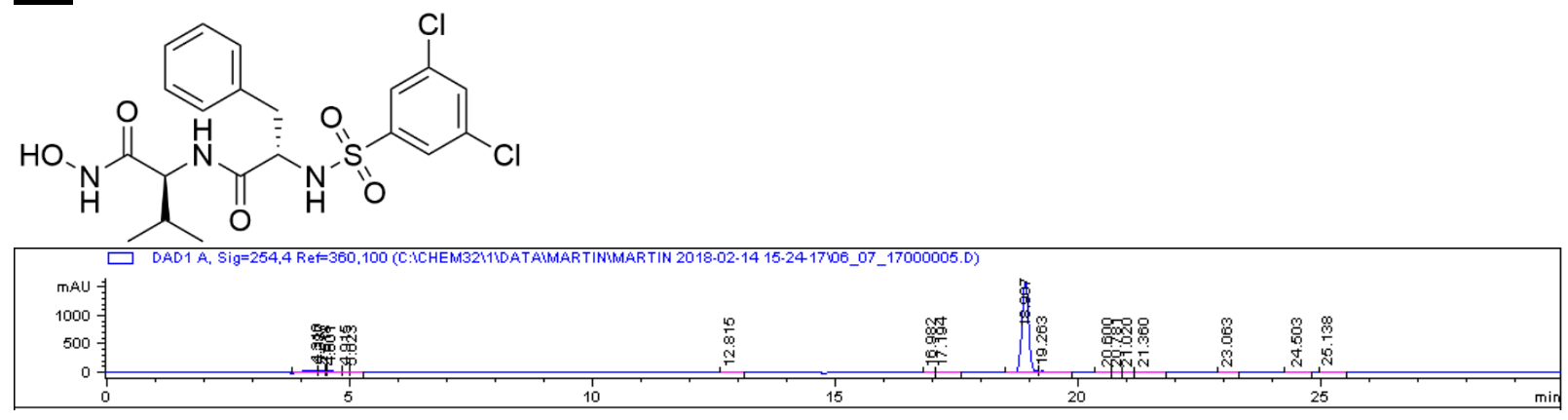




\section{NMR spectra of dipeptides 30-33}

All NMR spectrum were run in DMSO- $\mathrm{d}_{6}$ with $0.1 \% \mathrm{TMS}\left({ }^{13} \mathrm{C}\right.$ NMR solvent peak is at $39.52 \mathrm{ppm}$; ${ }^{1} \mathrm{H}$ NMR solvent peak is at 2.50ppm, with TMS peak at 0.0)

$\underline{30}$<smiles>CCCC(NC(=O)C(NS(=O)(=O)c1cc(Cl)cc(Cl)c1)C(CC)CC)C(=O)NO</smiles>
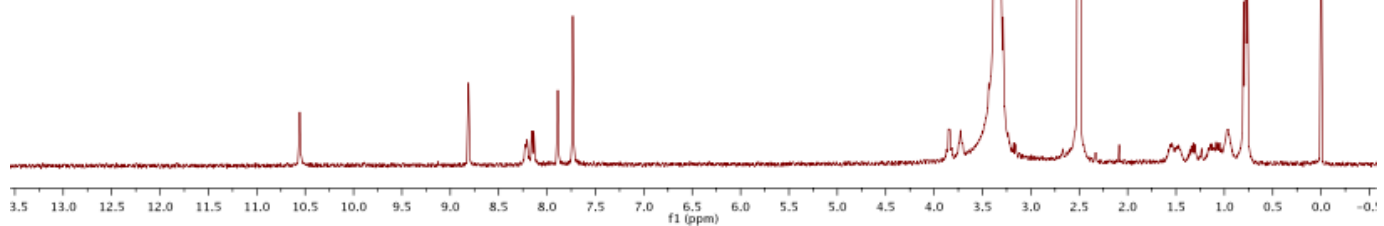<smiles>CCCC(NC(=O)C(NS(=O)(=O)c1cc(Cl)cc(Cl)c1)C(C)CC)C(=O)NO</smiles>

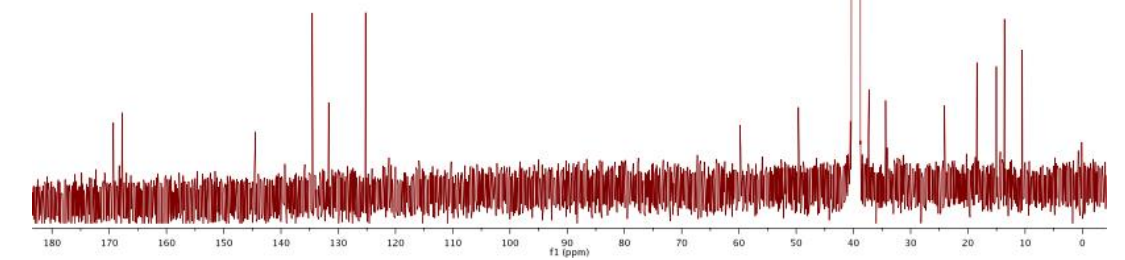

$\underline{31}$ 

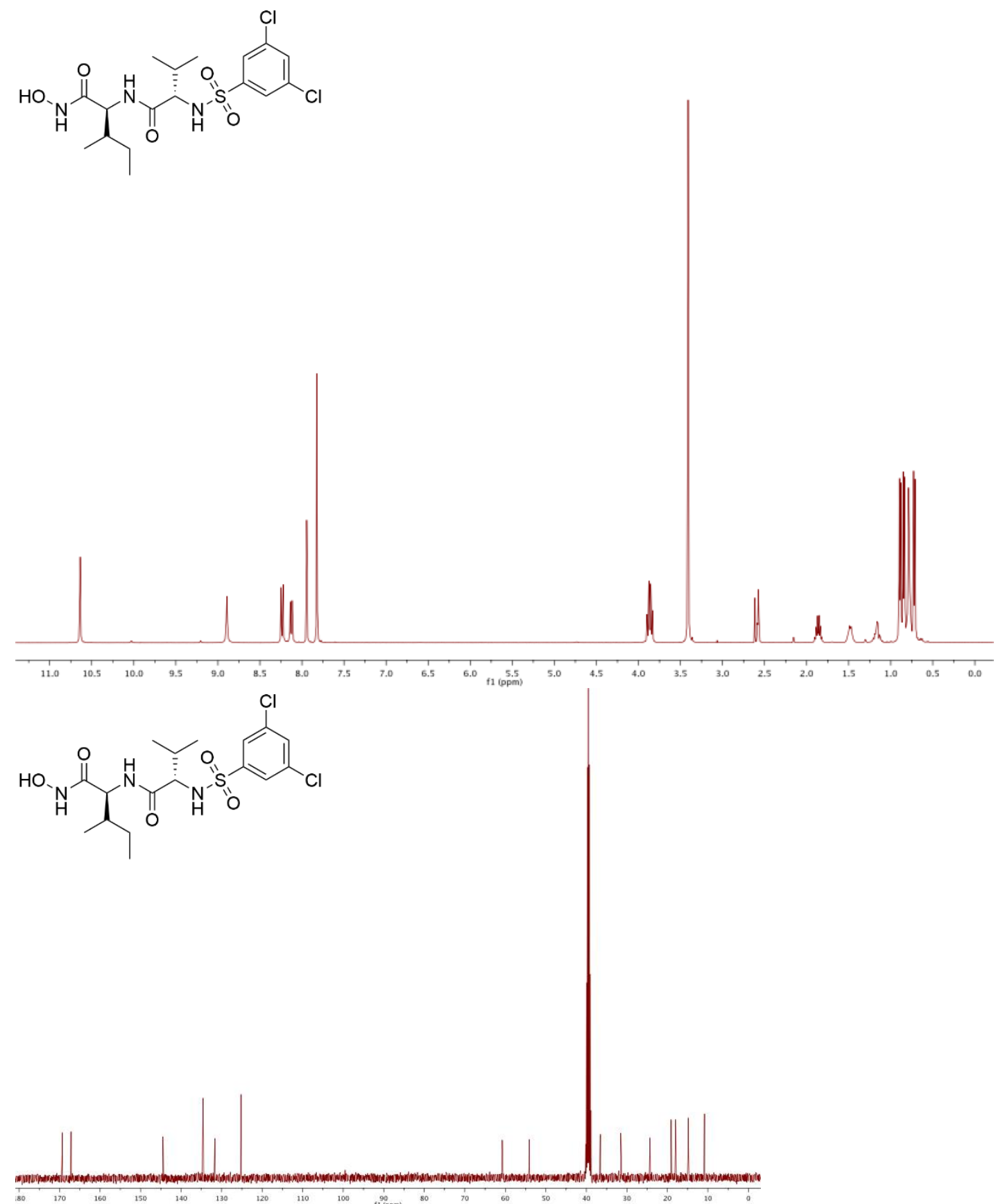
$\underline{32}$<smiles>CCC[C@H](NC(=O)[C@H](Cc1ccccc1)NS(=O)(=O)c1cc(Cl)cc(Cl)c1)C(=O)NO</smiles>

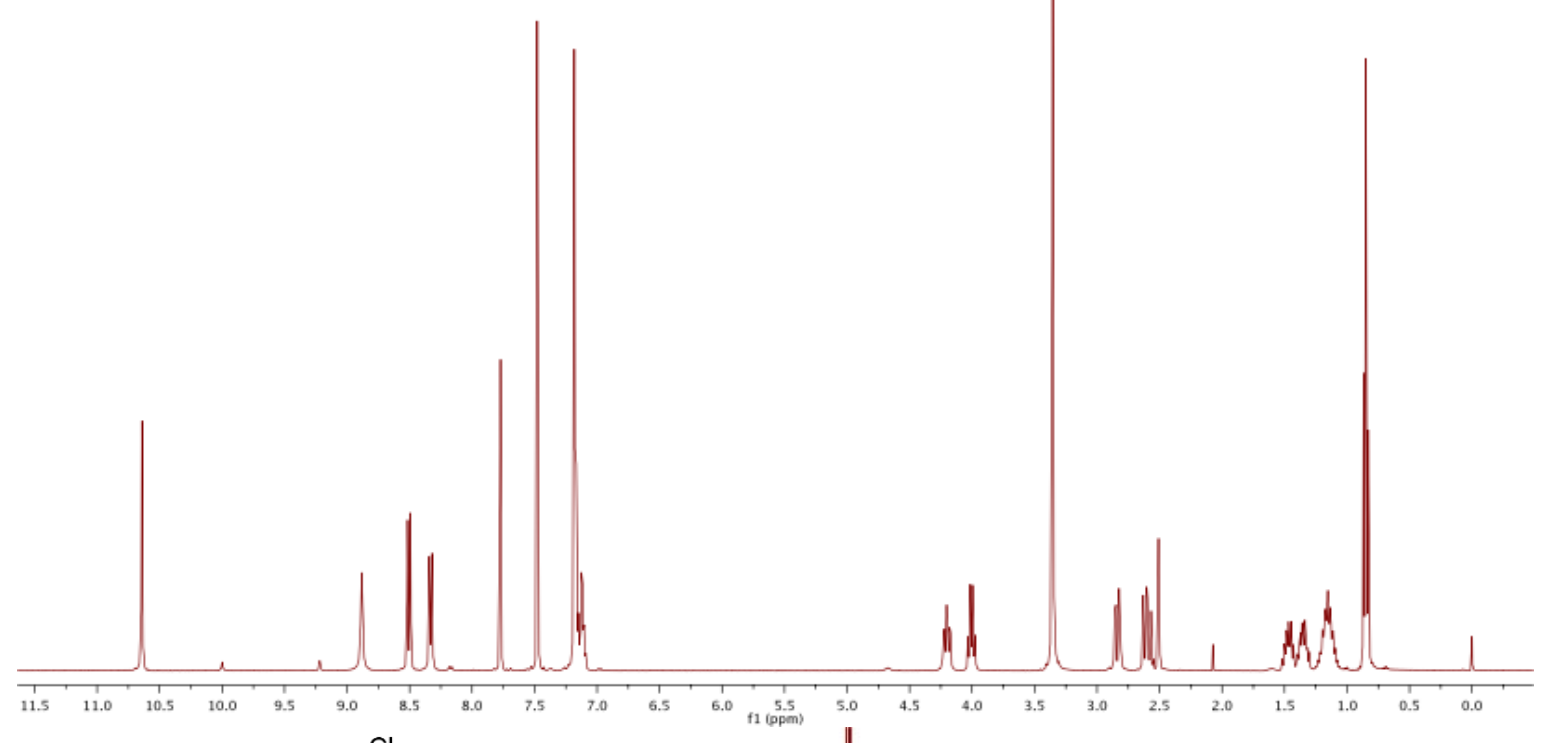<smiles>CCCC(NC(=O)[C@H](Cc1ccccc1)NS(=O)(=O)c1cc(Cl)cc(Cl)c1)C(=O)NO</smiles>

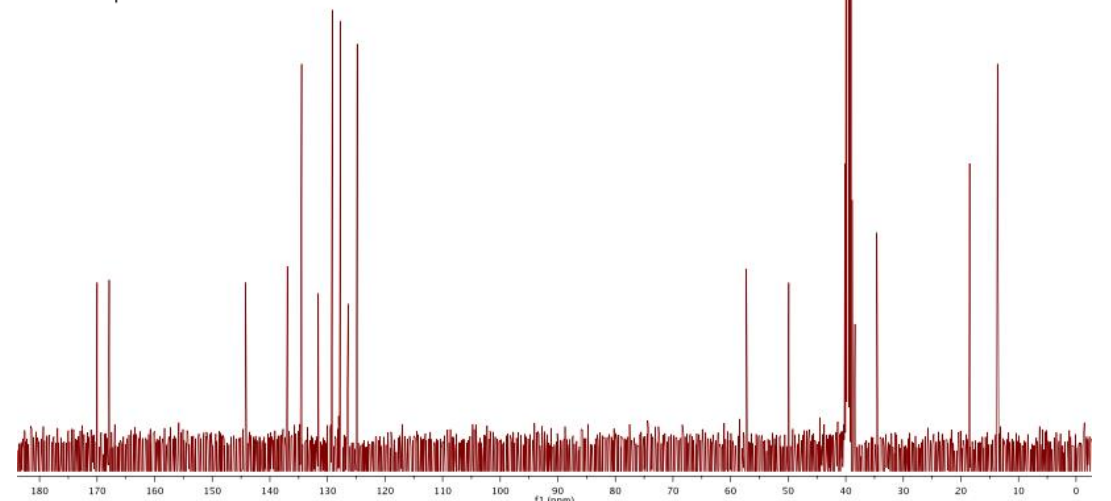


$\underline{33}$

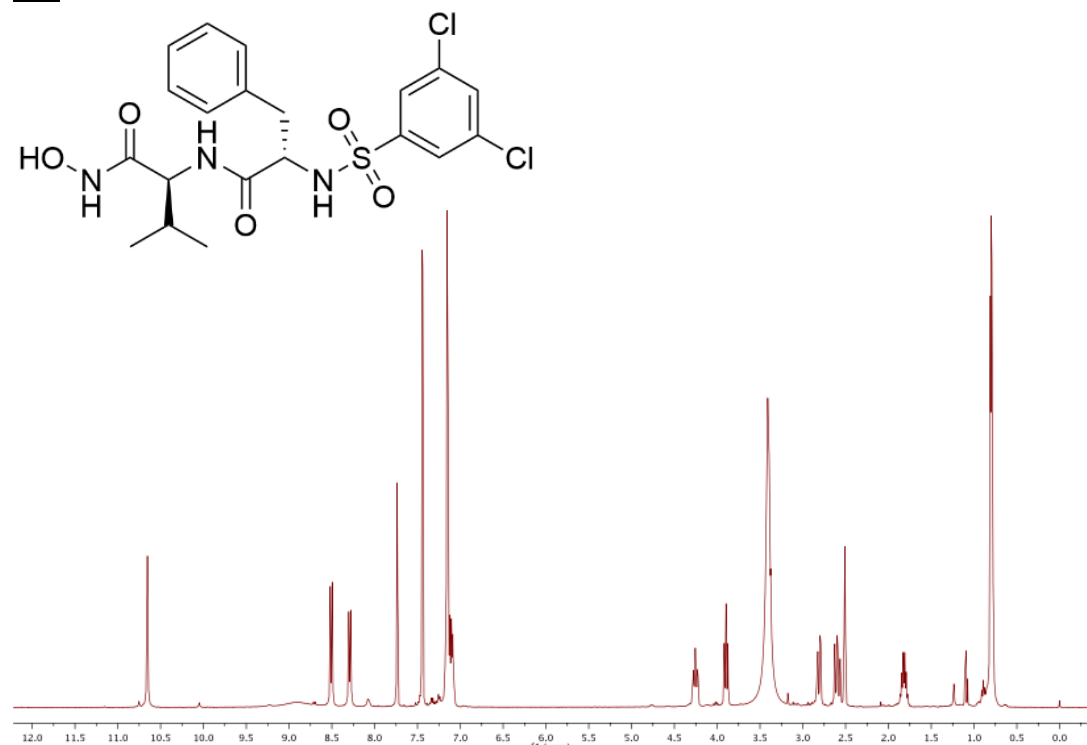<smiles>CC(C)[C@H](NC(=O)[C@H](Cc1ccccc1)NS(=O)(=O)c1cc(Cl)cc(Cl)c1)C(=O)NO</smiles>

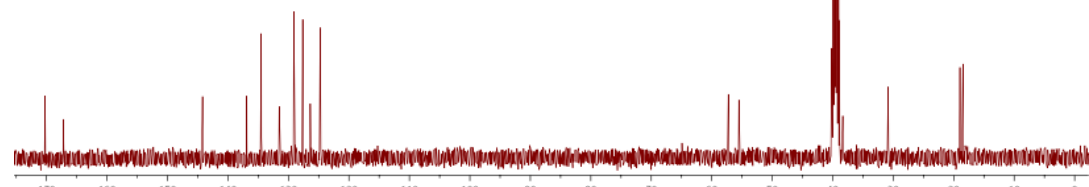

